patients had low Haemophilus IgG, 79\% of patients had low Pneumococcal IgG, and $1 \%$ of patients had low Tetanus IgG.

$37 / 48$ patients had low FAA; 29 of these patients were recommended to receive booster vaccines. $9 / 15$ of parents reported reduction of RTI post booster vaccine. 10/12 of patients had their FAA documented to have returned to normal.

Conclusions $60 \%$ of patients with low FAA had reduced RTI post booster vaccine. FAA should not be done in children less than 13 months of age as the booster dose is due at 12-13 months and a low level may not necessarily change management. FAA is a useful tool for investigating children with recurrent RTI.

\section{DIAGNOSING INFECTIOUS MONONUCLEOSIS IN PRIMARY CARE - CASE STUDIES FROM A PEDIATRIC OUTPATIENT CLINIC}

doi:10.1136/archdischild-2012-302724.0907

'R Bogdan, ${ }^{2,3} \mathrm{~A}$ A Anca, 'M Oros, 'C Codleanu, 'C Momarla, 'C Radu, 'L Baranga, 'E Topor, 'A Dumineca. 'Paediatrics, Medicover Clinic; ' 2 Paediatrics, Institute for Mother and Child Care 'Alfred Rusescu'; 'Paediatrics, 'Carol Davila' University of Medicine and Pharmacy, Bucharest, Romania

Background Although a common viral disease Infectious Mononucleosis may represent a diagnostic challenge for the primary care physician.

Objectives To describe the clinical and biological features of Infectious Mononucleosis by analizing cases diagnosed, treated and followed up in an outpatient pediatric clinic.

Materials and Methods We conducted a retrospective study consulting the electronical medical records of all the children who were given the diagnosis "Infectious Mononucleosis" over a period of 3 years.

Results 40 children (aged 2 to 18 years) were given this diagnose during the studied period. Out of these 3 cases were confirmed not to be "Infectious mononucleosis" being given an alternative diagnostic, 6 cases were not followed up for various reasons and were excluded from the study and 3 cases could not be confirmed because the parents refused blood withdrawal. 26 cases were confirmed serologically (positive Ig $M$ for Epstein Barr virus). Most prevalent symptom was enlarged lymph nodes (84\%), followed by altered general status (80.7\%), fever (53\%), exudative tonsilitis (34.6\%). Lymphocytosis and elevated glutamic pyruvic transaminase were the most prevalent biological signs (50\%) followed by elevated C reactive protein $(42.3 \%)$. One case was found with trombocytopenia and 1 case exibit signs and symptoms of rhabdomyolisis (elevated CK, LDH, GOT; muscle pain).

Conclusions Infectious mononucleosis may have polymorphic manifestations. One should consider this diagnostic especially when investigating fever that lasts longer than 4 days, enlarged lymph nods and exudative tonsilitis but be aware of particular forms of this disease.

\section{ENVIRONMENTAL RISK FACTORS FOR HEPATITIS A}

doi:10.1136/archdischild-2012-302724.0908

${ }^{1} \mathrm{~A}$ Bozaykut, 'RG Sezer, 'V Akcan, ${ }^{2} \mathrm{G}$ Aydemir, ${ }^{2} \mathrm{IA}$ Tanju, 'LP Seren, 'C Paketci. 'Department of Pediatrics, Zeynep Kamil Maternity and Childrens' Disease Training and Research State Hospital; '2Department of Pediatrics, GATA Teaching Hospital, Istanbul, Turkey

Background and Aims Hepatitis A virus (HAV) is an enteric viral infectious disease that is endemic in Turkey. Asymptomatic or subclinical infection often occurs in children, and symptomatic acute infections are more common in adolescents and young adults. In this study, we investigated the seropositivity for HAV and the associated socioeconomic factors in children aged between 2 and 18 years.
Methods A questionnaire was administered that addressed gender, age, number of household members, monthly family income, history of jaundice and immunization, number of rooms in the house, education level of the parents, day-care/school attendance, and type of water supply. The socioeconomic status score of each child was determined by summing the scores for monthly family income, education level of the parents, number of rooms in the house and number of people living in the house. Blood samples were collected and analyzed for anti-HAV IgG

Results Significant associations between anti-HAV seropositivity and socioeconomic status, age under 6 years old and attending daycare, a history of jaundice and monthly family income were found ( $p<0.001, p=0.003, p<0.001, p=0.04$, respectively). Only the association between the history of jaundice and anti-HAV seropositivity remained significant in the multivariate analysis, with an adjusted Odds ratio of 13.1 (range: $2.9-59.5 ; \mathrm{p}=0.001$ ).

Conclusions Our findings showed an inverse correlation between HAV seropositivity and socioeconomic status. A high in-house population and paternal education level were not a significant factor increasing the risk of anti-HAV positivity. However, as the maternal education level increased, less HAV positivity was recorded.

\section{ANALYSIS OF NEWBORN SCREENING - BORN EXPOSED TO TOXOPLASMOSIS IN PREGNANCY ALCIDES CARNEIRO HOSPITAL IN PETROPOLIS - RJ BRAZIL}

doi:10.1136/archdischild-2012-302724.0909

${ }^{1}$ A Veiga, 'MCB Soares, ${ }^{2 R}$ Barbosa, ${ }^{2 R}$ Taguti, ${ }^{2} \mathrm{MM}$ Azevedo, ${ }^{2} \mathrm{CC}$ Mouco, ${ }^{2} \mathrm{EO}$ Veiga, ${ }^{2} \mathrm{NV}$ Moliterno, ${ }^{2} \mathrm{FM}$ Moliterno. 'Paediatrics; ${ }^{1}$ Faculdade de Medicina de Petrópolis, Petrópolis, Brazil

Background and Aims Toxoplasmosis is a cosmopolitan infection caused by Toxoplasma gondii, clinical features varying from asymptomatic infection to severe systemic manifestations. Brazil has one of the highest incidence rates of congenital toxoplasmosis in the world with estimated rates of 1:3000 live births. Knowledge of the incidence, etiology, pathogenesis, diagnosis and management of infections during pregnancy, childbirth and neonatal period is relevant because it may cause damage to the fetus and newborn, representing a public health problem worldwide. The aim of this study is evaluate the quality of neonatal screening for congenital toxoplasmosis.

Methods Retrospective study based on data collected from the medical records of 39 newborns Alcides Carneiro Hospital (HAC) in Petropolis, Rio de Janeiro, Brazil, from July 2010 to February 2012 whose mothers had seroconversion for toxoplasmosis during pregnancy. We analyzed maternal serology and treatment and clinical manifestations, laboratory and radiological newborn.

Results Forty percent of pregnant women under which seroconverted in the 3rd trimester of pregnancy, 33\% at 2 and $13 \%$ in first trimester. Underwent treatment $35 \%, 15 \%$ and $0 \%$ respectively. There were no clinical manifestations of congenital toxoplasmosis, all showed negative IgM and IgG positive $62 \%$. In imaging tests, $5 \%$ had changed transfontanel ultrasound (49\% unknown), 1\% fundoscopy losses (51\% ignored), and skull radiography unchanged $(23 \%$ ignored).

Conclusion Given the survey data, we conclude that there was poor adherence to native implementation of adequate prenatal care, underestimation of suspected cases with disabilities in serological screening, limited availability of laboratory diagnostic capabilities and imaging.

910 PNEUMONIA IN CHILDHOOD: USE OF PENICILLIN AS MONOTHERAPY TREATMENT

doi:10.1136/archdischild-2012-302724.0910 